\title{
Modeling Future Projections of Temperature-Related Excess Morbidity due to Infectious Gastroenteritis under Climate Change Conditions in Japan
}

\author{
Daisuke Onozuka, ${ }^{1,2}$ Antonio Gasparrini, ${ }^{3,4}$ Francesco Sera, ${ }^{3}$ Masahiro Hashizume, ${ }^{5}$ and Yasushi Honda \\ ${ }^{1}$ Department of Preventive Medicine and Epidemiology, National Cerebral and Cardiovascular Center Research Institute, Osaka, Japan \\ ${ }^{2}$ Department of Health Communication, Kyushu University Graduate School of Medical Sciences, Fukuoka, Japan \\ ${ }^{3}$ Department of Public Health, Environments and Society, London School of Hygiene \& Tropical Medicine, London, UK \\ ${ }^{4}$ Centre for Statistical Methodology, London School of Hygiene \& Tropical Medicine, London, UK \\ ${ }^{5}$ Department of Pediatric Infectious Diseases, Institute of Tropical Medicine, Nagasaki University, Nagasaki, Japan \\ ${ }^{6}$ Faculty of Health and Sport Sciences, University of Tsukuba, Tsukuba, Japan
}

BACKGround: Climate change has marked implications for the burden of infectious diseases. However, no studies have estimated future projections of climate change-related excess morbidity due to diarrhea according to climate change scenarios.

ОвJECTIVES: We aimed to examine temperature-infectious gastroenteritis associations throughout Japan and project temperature-related morbidity concomitant with climate change for the 2090s.

MeтнoDs: Weekly time series of average temperature and morbidity for infectious gastroenteritis cases in the period 2005-2015 were collated from the 47 Japanese prefectures. A two-stage time-series analysis was adopted to estimate temperature-infectious gastroenteritis relationships. Time series of present and future average daily temperature fluctuations were projected for the four climate change scenarios of representative concentration pathways (RCPs) according to five general circulation models. Excess morbidity for high and low temperatures and the net change in the period 19902099 were projected for each climate change scenario by assuming the absence of adaptation and population alterations.

RESULTS: In the period 2005-2015, 11,529,833 infectious gastroenteritis cases were reported. There were net reductions in temperature-induced excess morbidity under higher emission scenarios. The net change in the projection period 2090-2099 in comparison with 2010-2019 was -0.8\% (95\% empirical confidence interval [eCI]: $-2.3,0.5)$ for RCP2.6, $-3.8 \%$ (95\% eCI: $-6.1,-1.7)$ for RCP4.5, $-5.1 \%$ (95\% eCI: $-7.7,-2.8)$ for RCP6.0, and $-9.1 \%$ (95\% eCI: $-15.5,-4.2)$ for RCP8.5, and the higher the emissions scenario, the larger the estimates reductions. Spatial heterogeneity in the temperature-morbidity relationship was observed among prefectures (Cochran $Q$ test, $p<0.001 ; I^{2}=62.0 \%$ )

ConCLusions: Japan may experience a net reduction in temperature-related excess morbidity due to infectious gastroenteritis in higher emission scenarios. These results might be because the majority of temperature-related diarrhea cases in Japan are attributable to viral infections during the winter season. Further projections of specific pathogen-induced infectious gastroenteritis due to climate change are warranted. https://doi.org/10.1289/ EHP4731

\section{Introduction}

Climate change is a key threat to human health across the globe and a challenge for public health practice (Watts et al. 2018). The frequency of climate change-related disasters has increased by $46 \%$ since 2000 (Watts et al. 2018). Economic losses due to climaterelated events, which amounted to $\$ 129$ billion USD in 2016, have similarly grown since 1990 (Watts et al. 2018). Several countries have begun evaluating vulnerabilities to climate change, establishing adaptation and mitigation methods, and distributing climate data to health services. However, the spread and degree to which these actions will shield populations from increasing health risks associated with climate change is unclear (Patz et al. 2005). Although recent evidence suggests that progress has been made in improving health resilience to climate effects and that climate change may markedly elevate temperature-related mortality (Benmarhnia et al. 2014; Gasparrini et al. 2017; Hajat et al. 2014; Lee and Kim 2016),

\footnotetext{
Address correspondence to Daisuke Onozuka, Department of Preventive Medicine and Epidemiology, National Cerebral and Cardiovascular Center Research Institute, 6-1 Kishibeshin-machi, Suita, Osaka 564-8565, Japan. Telephone: +81-6-6170-1070; Fax: +81-6-6170-1897. Email: onozukad@ ncvc.go.jp

Supplemental Material is available online (https://doi.org/10.1289/EHP4731).

The authors declare they have no actual or potential competing financial interests.

Received 11 November 2018; Revised 24 June 2019; Accepted 6 July 2019; Published 19 July 2019.

Note to readers with disabilities: $E H P$ strives to ensure that all journal content is accessible to all readers. However, some figures and Supplemental Material published in EHP articles may not conform to 508 standards due to the complexity of the information being presented. If you need assistance accessing journal content, please contact ehponline@niehs.nih.gov. Our staff will work with you to assess and meet your accessibility needs within 3 working days.
}

potential effects of climate on morbidity must be estimated, and the future impact of health threats arising from climate change may differ among diseases.

Diarrhea is an example of a global health problem that will not likely be solved by future economic development (WHO 2014). In 2015, an estimated 526,000 deaths due to diarrhea occurred among children younger than 5 years of age (Liu et al. 2016). A recent study estimated that in 2016, diarrhea cases and deaths were responsible for more than 40 million disability-adjusted life-years (DALYs) among children younger than 5 years of age (Troeger et al. 2018). Although the incidence of diarrheal disease may be undermined by environmental changes such as climate change, which damage urban infrastructure and reduce the overall availability of water (World Health Organization 2014), diarrheal disease transmission is complex and depends on a number of factors (Prüss et al. 2002), comprising both host susceptibility and environmental components (Guerrant et al. 2013; Walker et al. 2013). Additionally, infectious diarrhea can arise as a result of a variety of pathogens whose relative importance varies regionally (Kotloff et al. 2013; Walker et al. 2013). Therefore, previous studies that have aimed to quantify the burden of diarrhea have encountered problems with data quality and model specificity (Liu et al. 2016; Troeger et al. 2018). Nevertheless, as diarrhea is a leading cause of death and illness globally among children younger than 5 years of age (Troeger et al. 2018), studies on diarrhea are paramount for improving prediction estimates and aiding in the prioritization of mitigation and adaptation policies in the future.

The increase in concern about climate change over recent decades has led to the emergence of evidence supporting a relationship between climate and the incidence of diarrhea (World Health Organization 2014; Pachauri et al. 2014; Shuman 2010). In Japan, norovirus and rotavirus are two of the main causes of diarrhea in children (Thongprachum et al. 2015, 2016). Norovirus is a 
predominant winter virus, showing a marked peak in November and December with continual detection through the month of May. In contrast, rotavirus is most common in February and March (Thongprachum et al. 2015, 2016). Additionally, several studies conducted in Japan have reported that the overall prevalence of norovirus and rotavirus infection is $13.2-40.7 \%$ and $5.0-42.2 \%$, respectively, with the number of detected cases increasing with each winter in Japan (Thongprachum et al. 2015, 2016). A recent systematic review and meta-analysis showed a positive association between ambient temperature and all-cause diarrhea and bacterial diarrhea, but no association with viral diarrhea (Carlton et al. 2016). A large-scale modeling study that assessed projections of climate change-related rises in diarrhea based on $5 \mathrm{em}-$ pirical studies and 19 climate models suggested that climate change will bring increases in the risk of diarrhea. However, this study also found uncertainties related to projections of diarrhea due to climate change (Kolstad and Johansson 2011). Moreover, a systematic analysis of data from the Global Burden of Disease Study removed climate change as a global health risk factor due to insufficient empirical evidence for climate-diarrhea relationships (Lim et al. 2012). These findings suggest that climate change may raise heat-related diarrhea incidence, while concomitantly reducing cold-related diarrhea incidence. Although several studies have reported climate-related mortality due to diarrhea (World Health Organization 2014), to our knowledge, no studies have estimated future projections of climate change-related excess morbidity due to diarrhea according to climate change scenarios. Furthermore, the degree to which the anticipated reduction in cold-related diarrhea incidence can counter the rise in heat-related diarrhea incidence remains to be determined. Therefore, a more comprehensive understanding by modeling future projections of climate change-related diarrhea might help to facilitate the development of climate change mitigation and adaptation strategies and public health policies.

Here, we aimed to project the effect of climate change on temperature-attributable diarrhea morbidity using national surveillance data from all infectious gastroenteritis cases in Japan.

\section{Methods}

\section{Study Design}

We used a two-steps time-series modeling framework for projections of climate change effects on health, described in detail elsewhere (Gasparrini et al. 2017; Vicedo-Cabrera et al. 2019). Briefly, in the first step, we used a time-series analysis to assess the association between observed data on temperature and weekly morbidity due to infectious gastroenteritis in all 47 Japanese prefectures. Additionally, we acquired historical (1960-2005) and projected (2006-2099) average daily temperature time series according to climate change scenarios of the four representative concentration pathways (RCPs), RCP2.6, RCP4.5, RCP6.0, and RCP8.5, using five general circulation models (GCMs) (Warszawski et al. 2014). In the second step, we computed historical and future projections of excess morbidity in diarrhea attributable to temperature under each RCP using the estimated temperature-morbidity association curve, and modeled temperature and morbidity projections.

\section{Ethics Approval}

The contents of this study were approved by the Ethics Committee of the Kyushu University Graduate School of Medical Sciences. Given that this was a retrospective observational study referring specifically to the use of deidentified national surveillance data, there was no requirement to acquire informed consent.

\section{Data Sources}

We obtained national surveillance data on infectious gastroenteritis cases reported in the period 2005-2015 in all 47 prefectures of Japan from the National Institute of Infectious Diseases (NIID), Ministry of Health, Labour and Welfare, Japan. Infectious gastroenteritis became a notifiable disease in 1999 and is under systematic surveillance according to the Infectious Disease Control Law in Japan. Such surveillance is contributed to by $\sim 3,000$ sentinel medical institutions, which comprise approximately $8 \%$ of the total number of pediatric hospitals and clinics in Japan (Onozuka et al. 2010; Onozuka and Hashizume 2011; Onozuka 2014). A case definition of infectious gastroenteritis comprises clinical symptoms of sudden stomach ache, vomiting, diarrhea, dehydration, fever, nausea, and electrolyte abnormality. Although a report of the number of infectious gastroenteritis cases is generally required every week, this law does not necessitate sentinel medical institutions to disclose laboratory test data. The clinical data are reported electronically to the NIID, and the NIID's computer system is used to check and validate the data for consistency.

Additionally, we obtained data on average daily temperatures and precipitation for the period 2005-2015 from the Japan Meteorological Agency. Representative data were obtained from a single weather station located in an urban region of the capital city of each prefecture. Hourly measurements across $24 \mathrm{~h}$ were averaged to obtain average daily temperatures and precipitation. Additionally, we calculated the weekly means for average temperature and precipitation. Average weekly temperature was used as the main exposure index. Average weekly precipitation was used as the confounding factor because it may be a major driver of waterborne acute infectious gastroenteritis and because it may also evolve in the future due to climate change.

\section{Scenario Models}

We projected future temperature-related infectious gastroenteritis under four climate change scenarios according to models of climate change and morbidity. We acquired climate historical and projected time-series data for average daily temperatures from the database developed by the Inter-Sectoral Impact Model Intercomparison Project (ISI-MIP). This database includes time series of modeled average daily temperatures for historical (1960-2005) and projected (2006-2099) periods (Warszawski et al. 2014). Historical and projections of average daily temperatures were developed according to GCMs (Warszawski et al. 2014). We used the four RCP scenarios (RCP2.6, RCP4.5, RCP6.0, and RCP8.5), as detailed in the fifth IPCC report (van Vuuren et al. 2011a). The ISI-MIP used five publicly available representative GCMs (GFDL-ESM2M, HadGEM2ES, IPSL-CM5A-LR, MIROC-ESM-CHEM, and NorESM1-M) to reconstruct daily temperature series under each GCM, and these models were chosen as the representatives of the various GCMs developed in the fifth phase of the Climate Model Intercomparison Project (CMIP5) (Taylor et al. 2012; Warszawski et al. 2014). GCMs were developed by considering the differences in the impact of climate change at varying levels of global warming according to the four RCPs to produce the highest and lowest end-of-century forcings (Warszawski et al. 2014). The model outputs are adjusted for bias and reduced to $0.5^{\circ} \times 0.5^{\circ}$ spatial resolution (Warszawski et al. 2014). The modeled daily temperature time series for each prefecture in the projection period 1990-2099 was obtained by linking the coordinates with the appropriate grid cells containing the climate projections. From the daily mean temperature time series, we also derived the weekly average of mean temperature. When the modeled weekly temperature series are applied to exposure-response relationships estimated using observed weekly time series for average daily mean temperature, deviations between the 
modeled and observed weekly temperature series may produce biased results in the impact projections. Thus, we corrected the modeled daily temperature series using the bias-correction method, which recalibrated using the monthly mean observed daily temperature series (Hempel et al. 2013). This bias-correction approach preserves the long-term absolute temperature change in the simulations (Hempel et al. 2013). We computed the projected weekly time series of infectious gastroenteritis cases, showing the average weekly observed number across each year of the projection period (19902099).

\section{Statistical Analysis}

Predicting the exposure-response relationships. We used twostage time-series analysis to estimate the prefecture-specific nonlinear lag impact of temperature on infectious gastroenteritis, as described previously (Gasparrini et al. 2015, 2017; VicedoCabrera et al. 2019). Briefly, in the first stage, we investigated the association between temperature and infectious gastroenteritis in each prefecture through quasi-Poisson regression and distributed lags nonlinear models (DLNMs). We modeled the cross-basis function of weekly mean temperature with natural cubic spline function for the temperature dimension with three internal knots at the 10th, 75th, and 90th percentile of the prefecture-specific temperature distributions. We also included a natural cubic B-spline of time with 8 degrees of freedom per year to account for seasonal and long-term variations. Given that delayed effects of temperature on diarrhea have been known to be approximately 1 month (2 to 5 wk for food poisoning (Bentham and Langford 2001); 1 month for diarrhea (Checkley et al. 2000); 4 wk for noncholera diarrhea (Hashizume et al. 2007); 3 to 4 wk for infectious gastroenteritis (Onozuka et al. 2010; Onozuka and Hashizume 2011); 5 wk for Salmonella (Kovats et al. 2004); 6 wk for Campylobacter and Escherichia coli (Fleury et al. 2006; Naumova et al. 2007)), we examined lag periods of up to $4 \mathrm{wk}$ ( $28 \mathrm{~d}$ ) for temperature using a natural cubic-spline function with 3 internal knots place at equal distance in log scale (Gasparrini et al. 2010). Weekly mean precipitation was used as the confounding factor and was modeled using a natural cubic-spline function with 3 internal knots place at equal distance in log scale. The average dispersion parameter was 11.8 , suggesting overdispersion.

In the second stage, we combined prefecture-specific estimates using multivariate meta-regression models to predict the association between nationwide nonlinear temperature and morbidity (Gasparrini et al. 2012). Additionally, the spatial heterogeneity in temperature-morbidity curves may be partly explained as effect modification by prefecture-specific factors (Gasparrini and Armstrong 2013). To account for the effect modification attributed to different temperature distributions between prefectures, prefecture-specific gross domestic product (GDP), mean temperature, and temperature range were also included in the model as meta-predictors. We then derived the best linear unbiased prediction of the overall cumulative associations between temperature and morbidity in each prefecture. The best linear unbiased prediction represented a trade-off between the prefecture-specific association and the prefecture-pooled association. This approach enabled areas with a small number of weekly cases or a short time series to use information from larger populations sharing similar characteristics. This analysis method was detailed previously (Gasparrini et al. 2017; Vicedo-Cabrera et al. 2019).

Projection of the effect on morbidity. We projected excess morbidity due to temperature using the weekly temperature and morbidity time-series model by assuming the absence of adaptation and population alterations, according to previous studies (Gasparrini et al. 2015, 2017; Onozuka and Hagihara 2017). Briefly, we determined the minimum morbidity temperature with lowest total cumulative relative risk between temperature and infectious gastroenteritis between the 1st and 99th percentile of the prefecture-specific temperature distribution. We used the minimum morbidity temperature as a reference to calculate the attributable risk by recentering the natural cubic spline. The resulting value was defined as the optimal temperature. The total attributable number of infectious gastroenteritis cases as a result of nonoptimal temperatures was calculated as the sum of contributions from all weeks in the series. The ratio of this value to the total number of infectious gastroenteritis cases was defined as the total attributable fraction. Factors contributing to the low and high temperatures were determined by combining the subsets correlating to weeks with temperatures under or over the minimum morbidity temperature. The excess morbidity for individual prefectures and combinations of GCMs and RCPs were estimated. Subsequently, attributable fractions were calculated as GCM-ensemble averages based on the decade and RCP, with the respective total number of infectious gastroenteritis cases as the denominator. Using Monte Carlo simulations, empirical confidence intervals (eCIs) and the uncertainty in the predicted association between the exposure-lag-response and climate projections among GCMs were calculated. Details of this method were described previously (Gasparrini et al. 2017).

For sensitivity analysis, temperature-morbidity relationships were estimated by creating a synthetic daily time series of outcome. We generated a daily series for infectious gastroenteritis cases by assigning uniform daily outcome counts within each week. The choice to perform the sensitivity analysis at daily level was motivated by our aim to evaluate the information in the observed distribution (especially the variability) of the daily mean temperature. This information has been used in the bias-correction procedure, which is an important step in deriving projection of health impact. We computed the projected daily time series of infectious gastroenteritis cases, projecting the average synthetic daily counts across each year of the projection period (1990-2099). In a different type of sensitivity analysis, we used exposure-response curves calculated using weekly data, but we calibrated the projected time series of daily mean temperature using the observed distribution of daily mean temperature, and the time series of daily outcome were projected using uniform distribution of events within a week. For both simulations, we calculated prefecture-specific attributable fractions using the same procedure for the main analysis. All statistical analyses were conducted using the dlnm and mvmeta packages in $\mathrm{R}$ (version 3.5.1; R Development Core Team).

\section{Results}

Between 1 January 2005 and 31 December 2015, a total of $11,529,833$ infectious gastroenteritis cases were reported in the 47 prefectures of Japan, and the average weekly temperature was $15.6^{\circ} \mathrm{C}$. The annual mean incidence per 100,000 population was 818.5, ranging from 348.4 in Okinawa to $1,878.3$ in Oita (Table $\mathrm{S} 1)$. The prefecture-specific average weekly temperature was $9.5^{\circ} \mathrm{C}$ in Hokkaido (a major prefecture in the northern part of Japan), $16.7^{\circ} \mathrm{C}$ in Tokyo (a metropolitan prefecture), $17.1^{\circ} \mathrm{C}$ in Osaka (the second largest metropolitan prefecture), and $17.4^{\circ} \mathrm{C}$ in Fukuoka (a major prefecture in the southern part of Japan), and Japanese prefectures experienced a variation in the average daily temperature (Figure 1, Figure S1 and Table S1). The minimum morbidity temperature was identified as the 72 nd percentile for temperature at the national level, with prefecture-specific means of $18.2^{\circ} \mathrm{C}$ in Hokkaido, $23.0^{\circ} \mathrm{C}$ in Tokyo, $23.1^{\circ} \mathrm{C}$ in Osaka, and $23.1^{\circ} \mathrm{C}$ in Fukuoka (Figure 1).

The current variation in average temperature (2010-2019) and the projected rise at the end of the 21st century (2090-2099) in Japan according to the four RCP scenarios are shown in Figure S2. The projections show a clear marked increase in average 

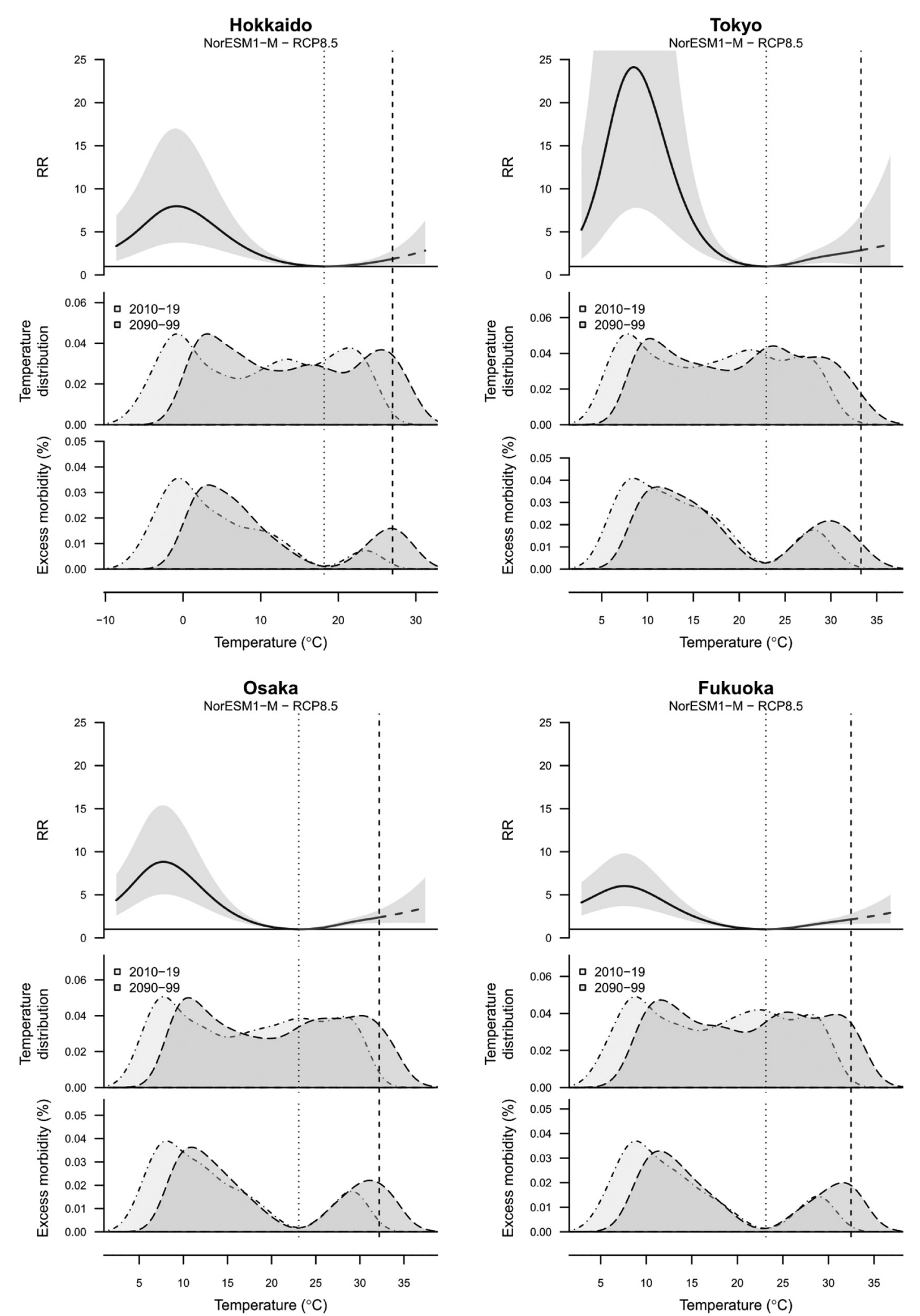

Figure 1. Temperature and excess morbidity in diarrhea in different climates. Hokkaido, Tokyo, Osaka, and Fukuoka Prefecture were selected because these are most populous prefectures of Japan, respectively. The top panels indicate the estimated exposure-response associations between the relative risks [95\% empirical confidence intervals $(\mathrm{eCI})]$, with minimum morbidity temperature used as reference, and the two portions identifying increased risks for cold and heat. The dashed part of the curve represents the extrapolation beyond the maximum temperature observed in the period 2010-2019 (dashed vertical line). The mid panels indicate the distribution of the modeled daily temperature series for the current period (2010-2019, light gray area) and at the end of the century (20902099, dark gray area), projected using a specific climate model (NorESM1-M) and scenario (RCP8.5). The bottom panels indicate the related distribution of excess morbidity in diarrhea, expressed as the excess morbidity (\%) related to nonoptimal temperatures compared with minimum morbidity temperature. 
temperatures under high-end emission scenarios (RCP6.0 and RCP8.5); however, this increase slowed or tended to be reduced after a number of decades under climate change scenarios that assume greenhouse-gas mitigation policies (RCP2.6 and RCP4.5) (Figure S2). A decrease in greenhouse-gas emissions by the end of the 21 st century may avert warming in Japan, with an average rise in temperature of $0.6^{\circ} \mathrm{C}$ (range: $0.4,0.9$ ) under RCP2.6, $1.8^{\circ}$ $\mathrm{C}$ (range: $1.4,2.2$ ) under $\mathrm{RCP} 4.5$, and $2.5^{\circ} \mathrm{C}$ (range: $1.8,3.0$ ) under RCP6.0 in comparison with $4.1^{\circ} \mathrm{C}$ (range: 3.0 , 4.9) under $\mathrm{RCP} 8.5$. The respective data from each prefecture are shown in Figures $\mathrm{S} 3$ and $\mathrm{S} 4$.

The total cumulative exposure-response curves (best linear unbiased predictions) showing the relative risk of infectious gastroenteritis according to temperature in the Japanese prefectures are summarized in Figure S5, along with the relevant lowest morbidity temperature and extreme temperature thresholds. The overall cumulative risk for infectious gastroenteritis showed generally a unimodal distribution at lower temperature and tended to increase at higher temperature. There was heterogeneity in the temperature-morbidity relationship across prefectures (Cochran $Q$ test, $p<0.001 ; I^{2}=62.0 \%$ ).

Projected patterns in heat- and cold-related excess morbidity in diarrhea in Japan according to three RCPs are summarized in Figure 2 and Table 1. Our findings demonstrated a similar pattern of a decrease in cold-related morbidity in diarrhea and slight rise in excess morbidity as a result of heat across the RCP scenarios. The projections showed steeper gradients for RCP8.5, whereas shallower trends were observed for scenarios that assumed mitigation strategies across the 21 st century. Our results projected a steep decrease in cold-related excess morbidity in diarrhea from $62.5 \%$ (95\% eCI: $57.4,65.6$ ) in the period $2010-2019$ to $49.5 \%$ (95\% eCI: 42.0, 57.1) in the period 2090-2099 under warming scenarios (RCP8.5), whereas the gradient gradually decreased under RCP2.6, ranged from $62.6 \%$ (95\% eCI: 57.4, 65.5) in the period 2010-2019 to $61.2 \%$ (95\% eCI: $56.0,64.9$ ) in the period 2090-2099. The heat-related excess morbidity in diarrhea was projected to rise from $5.7 \%(95 \%$ eCI: $4.4,6.8)$ to $9.7 \%(95 \%$ eCI: $4.9,12.0)$ under RCP8.5 across the same period, whereas the gradient gradually increased under RCP2.6, ranged from $5.8 \%$ (95\% eCI: $4.4,6.9)$ in the period $2010-2019$ to $6.3 \%$ (95\% eCI: $4.7,7.6$ ) in the period 2090-2099. The respective data from each prefecture are shown in Figures S6 and S7.

Temporal changes in excess morbidity in diarrhea in Japan according to three RCPs are shown in Figure 3 and Table 1. We found that the net difference in excess morbidity in comparison with the period 2010-2019 decreased gradually by the end of the 21 st century, and a net reduction in temperature-related excess morbidity due to infectious gastroenteritis ranged from $-0.8 \%$ (95\% eCI: $-2.3,0.5)$ for RCP2.6 to $-9.1 \%$ (95\% eCI: -15.5 , $-4.2)$ for RCP8.5 in the period 2090-2099. The respective data from each prefecture are shown in Figure S8 and Tables S2-S5. Although most prefectures were projected to experience a net reduction under RCP8.5, we found no significant net reduction in Okinawa prefecture.

We performed a sensitivity analysis to evaluate the exposureoutcome association at daily basis, and the estimated exposureresponse curves of the daily analysis were similar to the weekly one (Figures S5 and S9, respectively). We consider also a second sensitivity analysis on which the exposure-response curves were calculated using weekly data, but we calibrated the projected time series of daily mean temperature using the observed distribution of daily mean temperature, and we projected the time series of daily outcome using uniform distribution of events within a week. The estimates of attributable fractions for the period 2010-2019 obtained using the main and sensitivity analyses are reported in Tables S6-S8. The results of the sensitivity analysis are consistent with the main analysis and confirm the highest impact of cold with respect to heat. The excess morbidity calculated under the two sensitivity analyses are

\section{Japan (47 prefectures)}

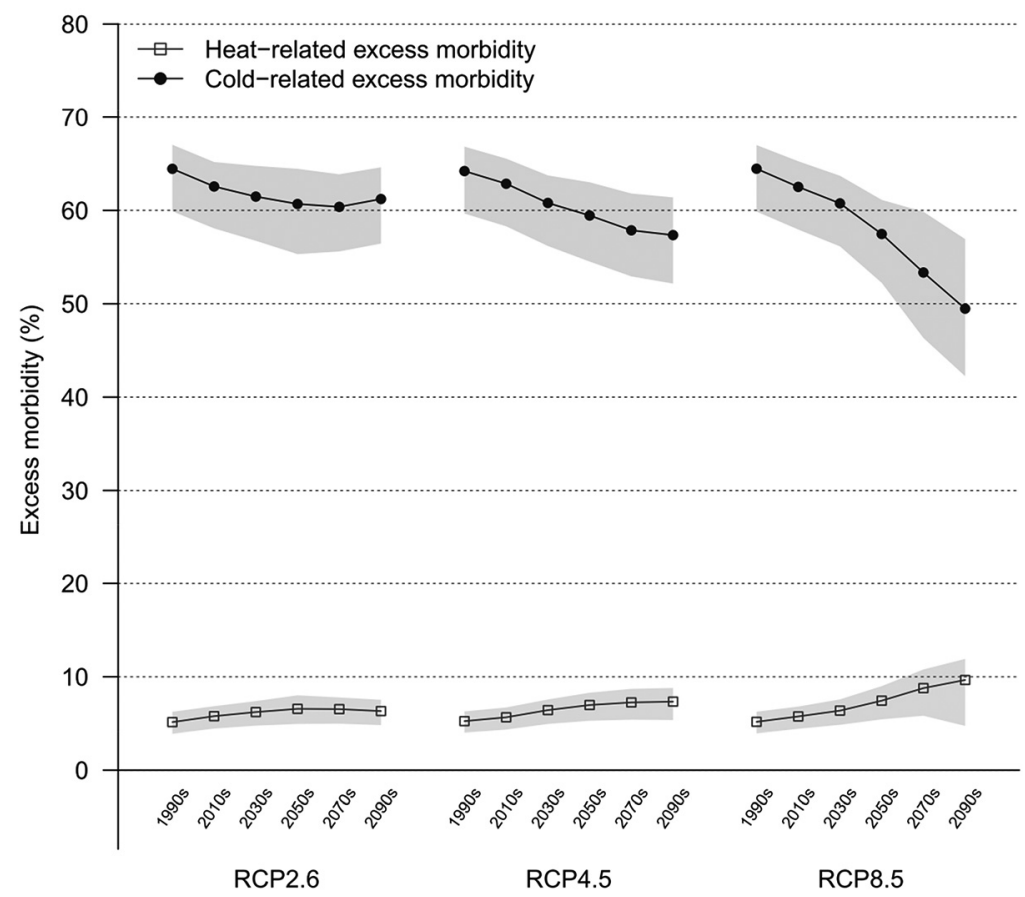

Figure 2. Trends in heat- and cold-related excess morbidity in diarrhea in Japan. The graph indicates the excess morbidity by decade as a result of heat and cold for three climate change scenarios (RCP2.6, RCP4.5, and RCP8.5). Estimates are presented as GCM-ensemble average decadal fractions. Shaded regions indicate 95\% empirical confidence intervals (eCIs). GCM, general circulation model; RCP, representative concentration pathway. 
Table 1. Heat-related, cold-related, and net excess morbidity in diarrhea (\%) with $95 \%$ empirical Confidence Interval (eCI) by period under four climate change scenarios (RCP2.6, RCP4.5, RCP6.0, and RCP8.5) in Japan. Heat-related and cold-related morbidity were estimated using a two-stage time-series regression model with quasi-Poisson family (Gasparrini et al. 2017). Estimates are presented as GCM-ensemble average decadal fractions.

\begin{tabular}{|c|c|c|c|c|}
\hline \multirow[b]{2}{*}{ Scenario } & \multirow[b]{2}{*}{ Effect } & \multicolumn{3}{|c|}{ Period } \\
\hline & & 2010-2019 & $2050-2059$ & 2090-2099 \\
\hline \multirow[t]{3}{*}{ RCP2.6 } & Heat & $5.8(4.4,6.9)$ & $6.6(4.9,8.1)$ & $6.3(4.7,7.6)$ \\
\hline & Cold & $62.6(57.4,65.5)$ & $60.7(54.9,64.7)$ & $61.2(56.0,64.9)$ \\
\hline & Net & - & $-1.1(-3.0,0.3)$ & $-0.8(-2.3,0.5)$ \\
\hline \multirow[t]{3}{*}{ RCP4.5 } & Heat & $5.7(4.3,6.8)$ & $7.0(5.2,8.3)$ & $7.3(5.2,8.9)$ \\
\hline & Cold & $62.9(57.7,65.9)$ & $59.4(54.1,63.2)$ & $57.4(51.7,61.6)$ \\
\hline & Net & - & $-2.1(-3.8,0.1)$ & $-3.8(-6.1,-1.7)$ \\
\hline \multirow[t]{3}{*}{ RCP6.0 } & Heat & $5.7(4.3,6.8)$ & $6.7(4.9,8.0)$ & $8.1(5.5,10.2)$ \\
\hline & Cold & $63.1(57.9,66.2)$ & $59.9(54.5,63.4)$ & $55.5(49.5,60.2)$ \\
\hline & Net & - & $-2.2(-3.6,-0.6)$ & $-5.1(-7.7,-2.8)$ \\
\hline \multirow[t]{3}{*}{ RCP8.5 } & Heat & $5.7(4.4,6.8)$ & $7.4(5.3,9.0)$ & $9.7(4.9,12.0)$ \\
\hline & Cold & $62.5(57.4,65.6)$ & $57.5(51.9,61.4)$ & $49.5(42.0,57.1)$ \\
\hline & Net & - & $-3.4(-5.6,-1.8)$ & $-9.1(-15.5,-4.2)$ \\
\hline
\end{tabular}

Note: - , no data; GCM, general circulation model; RCP, representative concentration pathway.

reported in Tables S9 and S10 and showed a similar pattern of the estimates using weekly counts data (Table 1).

\section{Discussion}

We estimated future projections in temperature-related excess morbidity due to infectious gastroenteritis throughout Japan using five GCMs and four RCPs. Our models projected a net decrease in temperature-related excess morbidity due to infectious gastroenteritis under higher emission scenarios in Japan. Our findings suggest that climate change may decrease the incidence of infectious gastroenteritis in Japan.

Our study showed that climate change may potentially lead to a net reduction in temperature-related infectious gastroenteritis in Japan. Our findings also predicted a marked decrease in cold- related excess morbidity in diarrhea under higher emission scenarios and a relatively mild rise in heat-related excess morbidity in diarrhea in Japan. These results are in agreement with recent reports based on long-term data on the scale of centuries to millennia of human epidemic events, which suggest that cooling, rather than warming, increases the incidence of human epidemics (Büntgen et al. 2016; Tian et al. 2017; Zhang et al. 2011). In contrast, a previous global study derived from shorter-term data projected a substantial increase in the risk of climate change-related diarrhea in six geographical regions (Kolstad and Johansson 2011). However, it is difficult to assess the evidence presented in this global study because it did not relate the final results to present disease burden. Additionally, future socioeconomic and demographic changes may decrease the effect of temperature on diarrheal disease transmission. Moreover, the discrepancy may

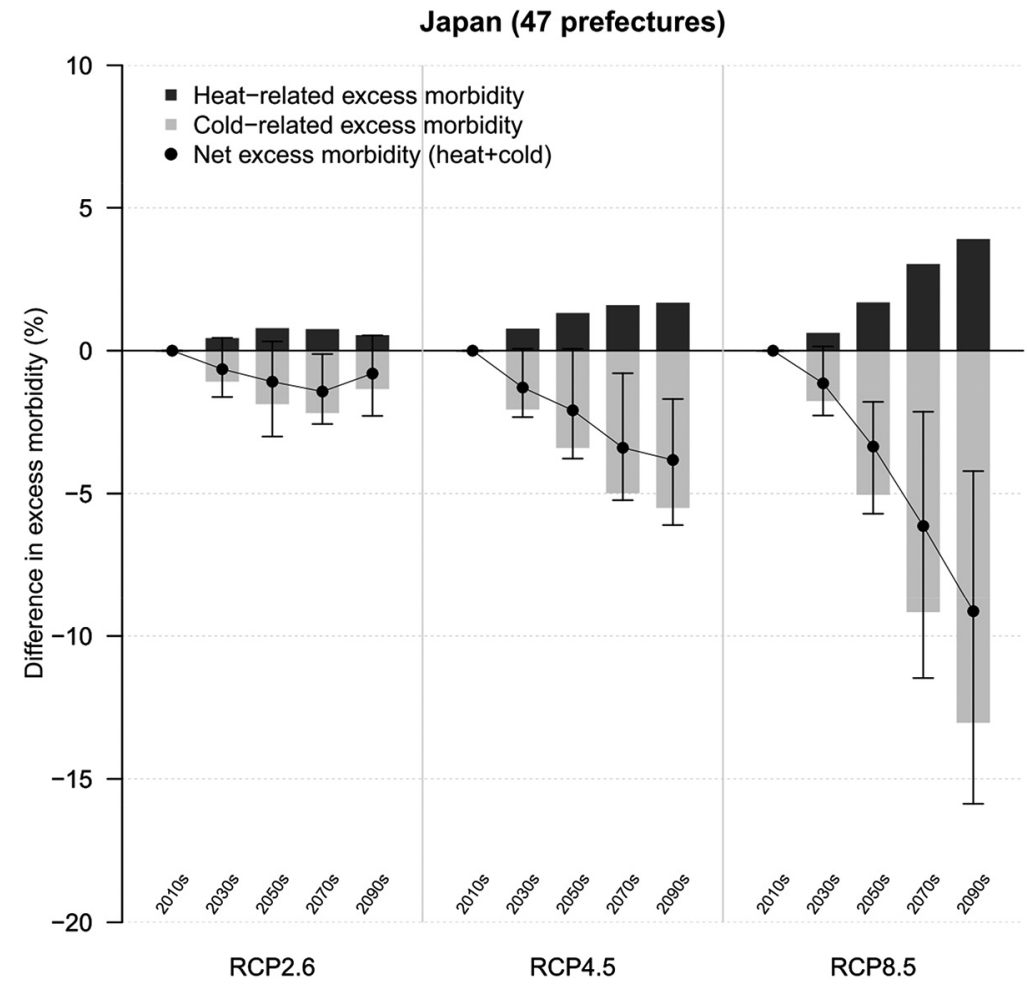

Figure 3. Deviations in excess morbidity in diarrhea in Japan over time. The graph indicates the change in excess morbidity by decade in comparison with 2010-2019 for three climate change scenarios (RCP2.6, RCP4.5, and RCP8.5). Estimates are presented as GCM-ensemble averages. Black vertical areas indicate $95 \%$ empirical confidence intervals (eCIs) of the net change. GCM, general circulation model; RCP, representative concentration pathway. 
also be because most previous studies that have investigated the impact of climate change on the prevalence of diseases mainly used short-term data (4 to $9 \mathrm{y}$ ). Our results emphasize the importance of further investigation into projections of global warming and the associated effect on morbidity due to infectious gastroenteritis by adjusting for future socioeconomic and demographic factors and more long-term data than are currently available.

Outdoor temperature may affect the various pathogens implicated in diarrheal diseases in differing ways in different regions. Evidence in Japan indicates an association between norovirus and rotavirus infection and low temperatures in comparison with the low number of cases detected in the summer months (Thongprachum et al. 2015, 2016). Recently, a systematic review and meta-analysis demonstrated a positive association between ambient temperature and the incidence of bacterial diarrhea, but not viral diarrhea (Carlton et al. 2016). These results suggest that the majority of temperature-related diarrhea cases in Japan are attributable to viral infections during the winter season. Our findings of a net reduction in infectious gastroenteritis due to global climate change are therefore biologically and geographically plausible in Japan or other countries in which the great majority of instances of infectious gastroenteritis are of viral origin. However, we were unable to assess pathogen-specific effects in our modeling, and the associations reported in our study cannot be extrapolated directly to the countries in which bacterial infectious gastroenteritis comprises a larger fraction of cases. Given that bacterial and viral organisms may exhibit varying responses to the impact of climate change, our findings likely demonstrate the effect of the most frequent cause of viral infectious gastrointestinal disease. Moreover, our study demonstrated significant spatial heterogeneity in the temperature-morbidity relationship among prefectures, suggesting that the effect of climate change on the incidence of diarrheal diseases may differ depending on the region as a result of spatial variability in the distribution of pathogens (Carlton et al. 2016). However, to generalize the effect of climate change without accounting for pathogen characteristics may not be accurate, and the actual association of temperature with diarrheal pathogens may be more complex, including specific clinical features such as duration, severity, dysentery, febrile illness, and vomiting (Platts-Mills et al. 2015). Further, the latency period of infectious gastroenteritis differs according to the pathogens, and these differences may also indicate a need for comparisons using various different distributions. Our findings should therefore be interpreted with this in mind, and additional studies are needed to determine the possible future impact of climate change on specific pathogenmediated infectious gastroenteritis in different regions and countries.

Our findings suggest that variations in temperature-related excess infectious gastroenteritis in Japan are proportional to the degree of global warming modeled in each of the RCP emission scenarios. We found that the largest net decrease in excess morbidity occurred for RCP8.5, which assumes very high greenhouse gas emissions (Pachauri et al. 2014). In contrast, the net decrease in excess morbidity was lower for RCP2.6, which assumes a limited increase in global average temperatures of $2^{\circ} \mathrm{C}$ following climatechange adaptation and mitigation policies (van Vuuren et al. 2011b). Although a recent study in Africa has reported that climate change may increase diarrheal disease outbreaks (Alexander et al. 2018), the direction and magnitude of this impact on morbidity may in fact differ in areas. There is insufficient knowledge about climate effects on different types of diseases, and our results emphasize the importance of further investigations into projections of global warming and the associated impacts on mortality and morbidity due to different pathogens.

Our results have practical implications for refining or adjusting estimates for climate change-related infectious gastroenteritis in future public health policies. Our study projects the greatest reduction in net excess infectious gastroenteritis morbidity in Japan due to climate change under higher emission scenarios. The majority of the excess morbidity was attributable to low temperatures, and heat was associated only with a small fraction of excess morbidity. Additionally, the reduction in temperaturerelated net excess morbidity is expected to be significant in scenarios of high greenhouse gas emissions. These findings are important because there may be no specific public health action for climate and diarrhea, and the current international dialog should be advised that the impact of climate change on diarrhea may vary by types of diseases and areas.

This study had several limitations. First, it was not possible to consider information about individual factors, such as demographic factors and socioeconomic status, in our analysis because of difficulties in collecting data. Thus, social and economic vulnerabilities were not accounted for in our projections of temperature-related morbidity associations for climate change scenarios. Assessing the association between temperature and diarrhea and stratifying by these factors would provide a better understanding of the future impact of temperature-diarrhea relationships. Additionally, future climate change-related diarrheal disease burden may depend on future emission scenarios as well as alterations in socioeconomic and demographic trends and public health interventions (Gething et al. 2010; Hodges et al. 2014). Temperature-related social or behavioral trends, such as treatment-seeking behaviors, the prevalence of coinfections, and infant care practices, may also alter the effect of climate change on the epidemiology of acute infectious gastroenteritis (Pitzer et al. 2011). Therefore, our results should not be interpreted as predictions of future excess morbidity but rather of possible outcomes for each of the specified but theoretical scenarios. Second, our projections are subject to uncertainty due to variation in the climate models and lack of precision in the estimated exposureresponse association (Benmarhnia et al. 2014). Moreover, our findings are restricted to the range of observable temperature data for present climate conditions, and a key assumption for the projections of the infectious gastroenteritis burden into the future is that the shape of associations stay the same over time. Although this assumption is likely adequate for short-term estimations of the effect of climate on health, evidence suggests that temperatures will surpass currently observed ranges, the consequences of which on health will be difficult to estimate (Mora et al. 2013). Third, there may be biases in our results because we could not adjust for immunity to and probability of person-to-person transmission and variations of infectious gastroenteritis in the susceptible population. Variations due to immunity to and the transmissibility of infectious diseases in the at-risk population may bias estimates of associations with temperature (Imai et al. 2015; Imai and Hashizume 2015). Additionally, poor immunity and the chance of transmissibility could increase in the next decade mainly due to aging of the population, and this effect may offset the effect of the increase in temperature in Japan. These potential biases may affect the interpretation of our results. Additional studies using more precise modeling methods are required to resolve these issues. Future studies should consider these important points.

\section{Conclusions}

In summary, our study projected a net reduction in temperaturerelated excess morbidity due to infectious gastroenteritis in Japan under higher-emission climate-change scenarios. Insufficient knowledge about climate effects on different types of diseases and areas is available, and further studies on longer-term projections of specific pathogen-induced infectious gastroenteritis due to climate change by adjusting for future demographic changes and adaptation are warranted. 


\section{Acknowledgments}

This work was supported by the Japan Society for the Promotion of Science (JSPS) KAKENHI Grant Nos. 15K08714, 16H05247, 18K11666, and 19H03900; the Medical Research Council UK (Grant ID: MR/M022625/1); and the Natural Environment Research Council UK (Grant ID: NE/R009384/1). The funding sources had no role in the study design, data collection, data analysis, data interpretation, or preparation of the manuscript. The authors thank all staff members at the local and national infectious disease surveillance centers in Japan.

\section{References}

Alexander KA, Heaney AK, Shaman J. 2018. Hydrometeorology and flood pulse dynamics drive diarrheal disease outbreaks and increase vulnerability to climate change in surface-water-dependent populations: a retrospective analysis. PLoS Med 15(11):e1002688, PMID: 30408029, https://doi.org/10.1371/journal.pmed.1002688.

Benmarhnia T, Sottile MF, Plante C, Brand A, Casati B, Fournier M, et al. 2014. Variability in temperature-related mortality projections under climate change. Environ Health Perspect 122(12):1293-1298, PMID: 25036003, https://doi.org/10. 1289/ehp.1306954.

Bentham G, Langford IH. 2001. Environmental temperatures and the incidence of food poisoning in england and wales. Int J Biometeorol 45(1):22-26, PMID: 11411411.

Büntgen U, Myglan VS, Ljungqvist FC, McCormick M, Di Cosmo N, Sigl M, et al. 2016. Cooling and societal change during the Late Antique Little Ice Age from 536 to around 660 AD. Nature Geosci 9(3):231-236, https://doi.org/10.1038/ngeo2652.

Carlton EJ, Woster AP, DeWitt P, Goldstein RS, Levy K. 2016. A systematic review and meta-analysis of ambient temperature and diarrhoeal diseases. Int $\mathrm{J}$ Epidemiol 45(1):117-130, PMID: 26567313, https://doi.org/10.1093/ije/dyv296.

Checkley W, Epstein LD, Gilman RH, Figueroa D, Cama RI, Patz JA, et al. 2000. Effect of El Niño and ambient temperature on hospital admissions for diarrhoeal diseases in Peruvian children. Lancet 355(9202):442-450, PMID: 10841124, https://doi.org/10.1016/s0140-6736(00)82010-3.

Fleury M, Charron DF, Holt JD, Allen OB, Maarouf AR. 2006. A time series analysis of the relationship of ambient temperature and common bacterial enteric infections in two Canadian provinces. Int J Biometeorol 50(6):385-391, PMID: 16575582, https://doi.org/10.1007/s00484-006-0028-9.

Gasparrini A, Armstrong B. 2013. Reducing and meta-analysing estimates from distributed lag non-linear models. BMC Med Res Methodol 13:1, PMID: 23297754, https://doi.org/10.1186/1471-2288-13-1.

Gasparrini A, Armstrong B, Kenward MG. 2010. Distributed lag non-linear models. Stat Med 29(21):2224-2234, PMID: 20812303, https://doi.org/10.1002/sim.3940.

Gasparrini A, Armstrong B, Kenward MG. 2012. Multivariate meta-analysis for nonlinear and other multi-parameter associations. Stat Med 31(29):3821-3839, PMID: 22807043, https://doi.org/10.1002/sim.5471.

Gasparrini A, Guo Y, Hashizume M, Lavigne E, Zanobetti A, Schwartz J, et al. 2015. Mortality risk attributable to high and low ambient temperature: a multicountry observational study. Lancet 386(9991):369-375, PMID: 26003380, https://doi.org/ 10.1016/S0140-6736(14)62114-0.

Gasparrini A, Guo Y, Sera F, Vicedo-Cabrera AM, Huber V, Tong S, et al. 2017. Projections of temperature-related excess mortality under climate change scenarios. Lancet Planet Health 1, (9):e360-e367, PMID: 29276803, https://doi.org/10. 1016/S2542-5196(17)30156-0.

Gething PW, Smith DL, Patil AP, Tatem AJ, Snow RW, Hay SI. 2010. Climate change and the global malaria recession. Nature 465(7296):342-345, PMID: 20485434, https://doi.org/10.1038/nature09098.

Guerrant RL, DeBoer MD, Moore SR, Scharf RJ, Lima AA. 2013. The impoverished gut-a triple burden of diarrhoea, stunting and chronic disease. Nat Rev Gastroenterol Hepatol 10(4):220-229, PMID: 23229327, https://doi.org/ 10.1038/nrgastro.2012.239.

Hajat S, Vardoulakis S, Heaviside C, Eggen B. 2014. Climate change effects on human health: Projections of temperature-related mortality for the UK during the 2020s, 2050s and 2080s. J Epidemiol Community Health 68(7):641-648, PMID: 24493740, https://doi.org/10.1136/jech-2013-202449.

Hashizume M, Armstrong B, Hajat S, Wagatsuma Y, Faruque AS, Hayashi T, et al. 2007. Association between climate variability and hospital visits for non-cholera diarrhoea in Bangladesh: effects and vulnerable groups. Int $\mathrm{J}$ Epidemiol 36(5):1030-1037, PMID: 17664224, https://doi.org/10.1093/ije/dym148.

Hempel S, Frieler K, Warszawski L, Schewe J, Piontek F. 2013. A trend-preserving bias correction-the ISI-MIP approach. Earth System Dynamics Discussions 4(1):219-236, https://doi.org/10.5194/esdd-4-49-2013.

Hodges M, Belle JH, Carlton EJ, Liang S, Li H, Luo W, et al. 2014. Delays reducing waterborne and water-related infectious diseases in China under climate change. Nat Clim Chang 4:1109-1115, PMID: 25530812, https://doi.org/10.1038/ nclimate2428.

Imai C, Armstrong B, Chalabi Z, Mangtani P, Hashizume M. 2015. Time series regression model for infectious disease and weather. Environ Res 142:319-327, PMID: 26188633, https://doi.org/10.1016/j.envres.2015.06.040.

Imai C, Hashizume M. 2015. A systematic review of methodology: time series regression analysis for environmental factors and infectious diseases. Trop Med Health 43(1):1-9, PMID: 25859149, https://doi.org/10.2149/tmh.2014-21.

Kolstad EW, Johansson KA. 2011. Uncertainties associated with quantifying climate change impacts on human health: a case study for diarrhea. Environ Health Perspect 119(3):299-305, PMID: 20929684, https://doi.org/10.1289/ehp.1002060.

Kotloff KL, Nataro JP, Blackwelder WC, Nasrin D, Farag TH, Panchalingam S, et al. 2013. Burden and aetiology of diarrhoeal disease in infants and young children in developing countries (the Global Enteric Multicenter Study, Gems): a prospective, case-control study. Lancet 382(9888):209-222, PMID: 23680352, https://doi.org/10.1016/S0140-6736(13)60844-2.

Kovats RS, Edwards SJ, Hajat S, Armstrong BG, Ebi KL, Menne B. 2004. The effect of temperature on food poisoning: a time-series analysis of salmonellosis in ten European countries. Epidemiol Infect 132(3):443-453, PMID: 15188714, https://doi.org/10.1017/s0950268804001992.

Lee JY, Kim H. 2016. Projection of future temperature-related mortality due to climate and demographic changes. Environ Int 94:489-494, PMID: 27316627 https://doi.org/10.1016/j.envint.2016.06.007.

Lim SS, Vos T, Flaxman AD, Danaei G, Shibuya K, Adair-Rohani H, et al. 2012. A comparative risk assessment of burden of disease and injury attributable to 67 risk factors and risk factor clusters in 21 regions, 1990-2010: a systematic analysis for the Global Burden of Disease Study 2010. Lancet 380(9859):2224-2260, PMID: 23245609, https://doi.org/10.1016/S0140-6736(12)61766-8.

Liu L, Oza S, Hogan D, Chu Y, Perin J, Zhu J, et al. 2016. Global, regional, and national causes of under-5 mortality in 2000-15: an updated systematic analysis with implications for the sustainable development goals. Lancet 388(10063):3027-3035, PMID: 27839855, https://doi.org/10.1016/S0140-6736(16)31593-8.

Mora C, Frazier AG, Longman RJ, Dacks RS, Walton MM, Tong EJ, et al. 2013. The projected timing of climate departure from recent variability. Nature 502(7470):183-187, PMID: 24108050, https://doi.org/10.1038/nature12540.

Naumova EN, Jagai JS, Matyas B, DeMaria A Jr, MacNeill IB, Griffiths JK. 2007. Seasonality in six enterically transmitted diseases and ambient temperature. Epidemiol Infect 135(2):281-292, PMID: 17291363, https://doi.org/ 10.1017/S0950268806006698.

Onozuka D. 2014. Effect of non-stationary climate on infectious gastroenteritis transmission in Japan. Sci Rep 4:5157, PMID: 24889802, https://doi.org/10.1038/ srep05157.

Onozuka D, Hagihara A. 2017. Out-of-hospital cardiac arrest risk attributable to temperature in Japan. Sci Rep 7:39538, PMID: 28045031, https://doi.org/10.1038/ srep39538.

Onozuka D, Hashizume M. 2011. Weather variability and paediatric infectious gastroenteritis. Epidemiol Infect 139(9):1369-1378, PMID: 21044404, https://doi.org/ $10.1017 /$ S0950268810002451.

Onozuka D, Hashizume M, Hagihara A. 2010. Effects of weather variability on infectious gastroenteritis. Epidemiol Infect 138(2):236-243, PMID: 19678972 , https://doi.org/10.1017/S0950268809990574.

Pachauri RK, Allen MR, Barros VR, Broome J, Cramer W, Christ R, et al. 2014. IPCC, 2014: Climate Change 2014: Synthesis Report. Contribution of Working Groups I, II and III to the Fifth Assessment Report of the Intergovernmental Panel on Climate Change. Geneva, Switzerland: IPCC.

Patz JA, Campbell-Lendrum D, Holloway T, Foley JA. 2005. Impact of regional climate change on human health. Nature 438(7066):310-317, PMID: 16292302 , https://doi.org/10.1038/nature04188.

Pitzer VE, Viboud C, Lopman BA, Patel MM, Parashar UD, Grenfell BT. 2011. Influence of birth rates and transmission rates on the global seasonality of rotavirus incidence. J R Soc Interface 8, (64):1584-1593, PMID: 21508015, https://doi.org/10.1098/rsif.2011.0062.

Platts-Mills JA, Babji S, Bodhidatta L, Gratz J, Haque R, Havt A, et al. 2015. Pathogen-specific burdens of community diarrhoea in developing countries: a multisite birth cohort study (MAL-ED). Lancet Glob Health 3(9):e564-575, PMID: 26202075, https://doi.org/10.1016/S2214-109X(15)00151-5.

Prüss A, Kay D, Fewtrell L, Bartram J. 2002. Estimating the burden of disease from water, sanitation, and hygiene at a global level. Environ Health Perspect 110:537-542, PMID: 12003760, https://doi.org/10.1289/ehp.110-1240845.

Shuman EK. 2010. Global climate change and infectious diseases. N Engl J Med 362(12):1061-1063, PMID: 20335580, https://doi.org/10.1056/NEJMp0912931.

Taylor KE, Stouffer RJ, Meehl GA. 2012. An overview of CMIP5 and the experiment design. Bull Amer Meteor Soc 93(4):485-498, https://doi.org/10.1175/BAMS-D11-00094.1.

Thongprachum A, Khamrin P, Maneekarn N, Hayakawa S, Ushijima H. 2016. Epidemiology of gastroenteritis viruses in Japan: prevalence, seasonality, and 
outbreak. J Med Virol 88(4):551-570, PMID: 26387663, https://doi.org/10.1002/ jmv.24387.

Thongprachum A, Takanashi S, Kalesaran AF, Okitsu S, Mizuguchi M, Hayakawa $S$, et al. 2015. Four-year study of viruses that cause diarrhea in Japanese pediatric outpatients. J Med Virol 87(7):1141-1148, PMID: 25881021, https://doi.org/ $10.1002 / \mathrm{jmv} .24155$.

Tian H, Yan C, Xu L, Büntgen U, Stenseth NC, Zhang Z. 2017. Scale-dependent climatic drivers of human epidemics in ancient China. Proc Natl Acad Sci USA 114(49):12970-12975, PMID: 29109246, https://doi.org/10.1073/pnas.1706470114.

Troeger C, Colombara DV, Rao PC, Khalil IA, Brown A, Brewer TG, et al. 2018. Global disability-adjusted life-year estimates of long-term health burden and undernutrition attributable to diarrhoeal diseases in children younger than 5 years. Lancet Glob Health 6, (3):e255-e269, PMID: 29433665, https://doi.org/10. 1016/S2214-109X(18)30045-7.

van Vuuren DP, Edmonds J, Kainuma M, Riahi K, Thomson A, Hibbard K, et al. 2011a. The representative concentration pathways: an overview. Climatic Change 109(1-2):5, https://doi.org/10.1007/s10584-011-0148-z.

van Vuuren DP, Stehfest E, den Elzen MGJ, Kram T, van Vliet J, Deetman S, et al. 2011b. RCP2.6: exploring the possibility to keep global mean temperature increase below $2^{\circ} \mathrm{C}$. Climatic Change 109(1-2):95, https://doi.org/10.1007/ s10584-011-0152-3.
Vicedo-Cabrera AM, Sera F, Gasparrini A. 2019. Hands-on tutorial on a modeling framework for projections of climate change impacts on health. Epidemiology 30(3):321-329, PMID: 30829832, https://doi.org/10.1097/EDE.0000000000000982.

Walker CLF, Rudan I, Liu L, Nair H, Theodoratou E, Bhutta ZA, et al. 2013. Global burden of childhood pneumonia and diarrhoea. Lancet 381(9875):1405-1416, PMID: 23582727, https://doi.org/10.1016/S0140-6736(13)60222-6.

Warszawski L, Frieler K, Huber V, Piontek F, Serdeczny 0, Schewe J. 2014. The InterSectoral Impact Model Intercomparison Project (ISI-MIP): project framework. Proc Natl Acad Sci USA 111(9):3228-3232, PMID: 24344316, https://doi.org/10.1073/ pnas. 1312330110.

Watts N, Amann M, Ayeb-Karlsson S, Belesova K, Bouley T, Boykoff M, et al. 2018. The Lancet countdown on health and climate change: from 25 years of inaction to a global transformation for public health. Lancet 391(10120):581-630, PMID: 29096948, https://doi.org/10.1016/S0140-6736(17)32464-9

WHO (World Health Organization). 2014. Quantitative Risk Assessment of the Effects of Climate Change on Selected Causes of Death, 2030s and 2050s. Hales S, Kovats K, Lloyd S, Campbell-Lendrum D, eds. Geneva, Switzerland: World Health Organization.

Zhang DD, Lee HF, Wang C, Li B, Pei Q, Zhang J, et al. 2011. The causality analysis of climate change and large-scale human crisis. Proc Natl Acad Sci USA 108(42):17296-17301, PMID: 21969578, https://doi.org/10.1073/pnas.1104268108. 